\title{
AVALIAÇÃO DE MÉTODOS DE EXTRAÇÃO DO ARILO E TRATAMENTO COM ETHEPHON EM SEMENTES DE Passiflora giberti N.E. Brown PELOS TESTES DE GERMINAÇÃO E DE TETRAZÓLIO ${ }^{1}$
}

\author{
GISELA FERREIRA ${ }^{2}$, ALESSANDRA MARIA DETONI ${ }^{3}$, SAIONARA MARIA TESSER ${ }^{4}$ E MARLENE M. MALAVASI ${ }^{2}$
}

\begin{abstract}
RESUMO - Com o objetivo de avaliar o efeito de dois métodos de extração de arilo e cinco concentrações de ethephon em sementes de Passiflora giberti N.E.Brown, empregou-se o teste de germinação e de tetrazólio para a realização deste experimento, no Laboratório de Tecnologia de Sementes da Universidade Estadual do Oeste do Paraná - UNIOESTE, campus de Marechal Cândido Rondon, no período de 01/06 a 03/07/01. O delineamento foi o inteiramente casualizado com cinco repetições de 25 sementes por parcela. Os frutos foram coletados em Marechal Cândido Rondon e os tratamentos foram constituídos pela combinação de dois tipos de extração do arilo e embebição das sementes em cinco concentrações de ethephon por cinco horas. A semeadura para o teste de germinação foi realizada em rolos de papel germitest mantidos em câmara de germinação com temperatura alternada $\left(25-30^{\circ} \mathrm{C}\right)$. O teste de tetrazólio foi feito no lote de sementes antes da instalação do experimento e no final do teste de germinação, 30 dias após a semeadura. Os resultados demonstram que ocorerram interações significativas entre os métodos de extração do arilo e as concentrações de ethephon para a vitalidade de sementes. Pode-se observar que somente na extração por fermentação com a concentração de $600 \mathrm{mg} .1^{-1}$ verificou-se diminuição significativa na vitalidade das sementes, diferindo dos demais tratamentos. Na extração do arilo por fricção com pano todas as concentrações demonstraram-se semelhantes. Os métodos de extração do arilo não afetaram a vitalidade das sementes de Passiflora giberti N.E. Brown com presença de dormência, exceto quando se empregou $600 \mathrm{mg} .1^{-1}$ de ethephon. Tratamentos com ethephon não foram adequados para proporcionar a germinação das sementes.
\end{abstract}

Termos para indexação: Passiflora giberti, germinação, extração, ethephon.

EVALUATION OF TWO ARIL EXTRACTION METHODS AND ETHEPHON TREATED Passiflora giberti N.E. Brown SEEDS THROUGH TETRAZOLIUM AND GERMINATION TESTS

\begin{abstract}
The effect of two aril extraction methods on Passiflora giberti N.E. Brown and seeds treated with five ethephon concentrations was evaluated through germination and tetrazolium test. This study was carried out at Seed Laboratory, UNIOESTE, Marechal Cândido Rondon, in the State of Paraná, from 01/06 to 03/07/01. The experimental design was entirely casualized with five repetitions of 25 seeds each. The fruits were collected in Marechal Cândido Rondon and treated with the combination of two extraction types and five ethephon concentrations. The ethephon soaking period was five hours. Seeds were germinated on paper rolls at alternated temperature of $25-30^{\circ} \mathrm{C}$. The tetrazolium test was performed at the begin and at the end of 30 day germination test. There were significant interactions between aril extraction methods and ethephon concentrations for the percentage of viable seeds. It was observed a significant decrease in the percentage of vitalily on seeds extracted with fermentation and treated with ethephon at
\end{abstract}

\footnotetext{
${ }^{1}$ Aceito para publicação em 31.12.2001

2 Prof ${ }^{\mathrm{a}}$ Adjunto, Dra ${ }^{\mathrm{a}}$, Centro de Ciências Agrárias - UNIOESTE; Rua Pernambuco, 1777, 85960-000, Marechal Cândido Rondon-PR; e-mail: giferreira@unioeste.br; malavasi@unioeste.br
}

\footnotetext{
3 Acadêmica do curso de Agronomia - UNIOESTE; bolsista PIBIC UNIOESTE.

${ }^{4}$ Acadêmica do curso de Agronomia - UNIOESTE; bolsista Fundação Araucária.
} 
$600 \mathrm{mg} .1^{-1}$. In the aril cloth friction extraction method all ethephon concentrations had similar effect on seed vitality. The seeds of Passiflora giberti were dormant and the aril extraction methods didn't effect seed vitalily, except when it was used $600 \mathrm{mg}^{-1} 1^{-1}$ of ethephon. The treatments with ethephon did not promote seed germination.

Index terms: Passiflora giberti, germination, extraction, ethephon.

\section{INTRODUÇÃO}

O maracujazeiro pode ser propagado de forma sexuada através de sementes e assexuada pela utilização da estaquia, enxertia, alporquia e cultura de tecidos in vitro. A semeadura tem preferência em relação aos métodos assexuados devido à facilidade do processo e ao tempo de formação das mudas, que é menor.

Entre as espécies do gênero Passiflora, a Passiflora giberti N.E. Brown é pouco estudada, principalmente em relação à germinação, ao vigor, às condições de armazenamento, vitalidade e longevidade das sementes. A utilização de $P$. giberti como porta-enxerto para $P$. edulis Sims f. flavicarpa Degner é uma medida promissora para controle da morte prematura de plantas, sendo considerada resistente por Oliveira et al. (1986) e tolerante por Menezes et al. (1994).

Existem diversas informações quanto à germinação de sementes de maracujá, porém é unânime a afirmativa de que o início e o término da germinação de sementes das Passifloráceas ocorrem de forma irregular, podendo este período ser de dez dias a três meses, o que dificulta a formação de mudas devido à grande desuniformidade (Kuhne, 1968; Akamine et al., 1956 e Luna, 1984).

A dormência é um fator importante no estudo das sementes de Passifloráceas, uma vez que autores como Almeida et al. (1988) relatam a baixa germinação encontrada em sementes consideradas fisiologicamente maduras, sugerindo a existência de outros fenômenos interferindo no processo. Para Morley-Bunker (1980) o mecanismo de dormência que ocorre na família das Passifloráceas é o da entrada de água para o interior da semente, devido a dureza do tegumento. Porém, Ferreira (1998) observou que as sementes de $P$. giberti não apresentam impedimentos para a entrada de água no seu interior.

Além de fatores internos existem também fatores externos à semente que podem interferir na germinação, sendo que o método de extração de arilo pode ser um deles. São José \& Nakagawa (1987) observaram que métodos envolvendo a fermentação das sementes foram, de modo geral, prejudiciais à qualidade das mesmas e verificaram, também, que a presença de arilo contribuiu para diminuir a porcentagem de germinação em sementes recém extraídas de Passiflora edulis f. flavicarpa. Sementes fermentadas, com e sem arilo, apresentaram resultados semelhantes, variando de $75,5 \%$ a $82,5 \%$ de germinação, porém, sempre menores do que os das sementes sem arilo e secas ao sol $(85 \%$ de germinação para sementes secas por um dia e $89 \%$ para sementes secas por três dias). Ainda em relação a métodos de extração, São José \& Nakagawa (1988) observaram que a fermentação prejudicou a qualidade de sementes de Passiflora edulis f. flavicarpa, em relação ao vigor, a velocidade de emergência, ao comprimento e ao peso médio da plântula. Por outro lado, a fermentação beneficiou a porcentagem de germinação. Os autores observaram também, que a extração do arilo, manual ou por liqüidificador, não afetou a qualidade das sementes.

Outro mecanismo de dormência que pode estar envolvido e que deve ser levado em consideração é o balanço hormonal nas sementes, pois as elevadas concentrações de inibidores podem afetar negativamente a germinação, necessitando do uso de reguladores vegetais para acelerar o processo germinativo. De acordo com Abeles et al. (1992), a promoção da germinação pelo etileno foi descrita pela primeira vez por Vacha \& Harvey (1927).

O etileno age na germinação facilitando e acelerando o transporte das enzimas, sintetizadas pela ação do ácido giberélico (GA) na camada de aleurona até o endosperma, onde esstas enzimas (alfa amilase, proteases, ribonucleases, etc.) vão atuar na degradação das reservas (amido, proteína, ácido ribonucleico) e na promoção da germinação e formação posterior da plântula (Felippe, 1979). O etileno atua diferentemente entre as espécies, Mattoo \& Suttle (1991) relatam que aplicações de etileno podem ser antagônicas ao $\mathrm{GA}_{3}$, resultando em reações opostas, além do que, o etileno pode inibir ou aumentar a síntese de alfa amilase e superar a dormência em algumas espécies e promove a germinação em outras, como em sementes de alface, amendoim, girassol e maçã, sendo ineficiente em algumas sementes e agindo negativamente em outras. Em relação à Passiflora giberti, Ferreira (1998) verificou que o emprego de etileno, na concentração de $150 \mathrm{mg} .1^{-1}$ foi benéfico no processo germinativo, bem como, a mistura de citocinina e ácido giberélico $\left(\mathrm{GA}_{3} 50 \mathrm{mg} . \mathrm{l}^{-1}+\right.$ CK30mg. ${ }^{1-1}$ ), embora somente o etileno tenha promovido $45 \%$ 
de germinação, superior àquela obtida na mistura de $\mathrm{GA}_{3}+\mathrm{CK}$ a qual foi de $40 \%$ e que os dois tratamentos foram superiores à testemunha.

Deste modo, realizou-se este trabalho com o objetivo de avaliar o efeito de dois métodos de extração de arilo e cinco concentrações de ethephon em sementes de Passiflora giberti N.E. Brown, empregando-se o teste de germinação e de tetrazólio.

\section{MATERIAL E MÉTODOS}

O experimento foi realizado no laboratório de Tecnologia de Sementes da Universidade Estadual do Oeste do Paraná UNIOESTE, Campus de Marechal Cândido Rondon/PR, no período de 01/06 a 03/07/01.

As sementes de Passiflora giberti foram obtidas de frutos maduros coletados no município, com pesos variando de $7 \mathrm{~g}$ a 22g. Os métodos de extração do arilo utilizados foram a fricção com pano e a fermentação durante quatro dias. Após a remoção do arilo as sementes foram secas à sombra por cinco dias. Com as sementes obtidas em cada um dos métodos de extração, formou-se dois sub-lotes de sementes, nos quais determinou-se o grau de umidade e executou-se o primeiro teste de tetrazólio.

Para a determinação do grau de umidade foram empregadas quatro repetições de 25 sementes cada, utilizando estufa com circulação forçada de ar a $105 \pm 3^{\circ} \mathrm{C}$, por 24 horas, segundo Brasil (1992). As sementes com arilo extraído por fricção com pano apresentaram em média 14,8\% de umidade e $99 \%$ de sementes viáveis. As sementes com arilo extraído por fermentação apresentaram $10 \%$ de umidade e $95 \%$ de sementes viáveis.

O teste de tetrazólio foi realizado antes da aplicação dos tratamentos com ethephon, para a verificação da viabilidade das sementes, por ser considerado um método rápido de avaliação (Brasil, 1992). Foram utilizadas quatro repetições com 25 sementes para cada um dos dois sub-lotes que representavam os tratamentos de extração. As sementes foram embebidas em água por 24 horas, posteriormente foram cortadas longitudinalmente e colocadas em solução $0,075 \%$ por três horas. Os tecidos vivos e vigorosos apresentaram coloração vermelha ou rosa brilhante e limpa; tecidos mortos ou não viáveis estavam descoloridos ou com vermelho intenso (Malavasi et al., 2001).

Para a implantação do trabalho, empregou-se o delineamento experimental inteiramente casualizado com 10 tratamentos e cinco repetições de 25 sementes por parcela. Os tratamentos foram constituídos pela combinação entre dois métodos de extração do arilo (fricção e fermentação) e cinco concentrações de ethephon (zero, 150, 300, 450 e $\left.600 \mathrm{mg} \cdot 1^{-1}\right)$.

Os tratamentos com ethephon corresponderam à imersão das sementes por período de cinco horas, em soluções com diferentes concentrações do i.a. Utilizou-se o sistema de oxigenação promovida através de bombas de aquário. A fonte de ethephon foi o produto comercial Ethrel, composto por $240 \mathrm{~g} . \mathrm{l}^{-1} \mathrm{de}$ ácido 2-cloroetil-fosfônico e $865 \mathrm{~g} / 1$ de ingredientes inertes. Após os tratamentos aplicou-se às sementes o fungicida Captan (N-triclorometiltio-4-ciclo-hexeno-1,2 dicarboximida), com a finalidade de prevenir possíveis contaminações nas sementes.

A semeadura do teste de germinação foi realizada em rolos de papel germitest, com cinco repetições de 25 sementes para cada tratamento. Os tratamentos foram mantidos em câmara de germinação no escuro e com temperatura alternada de $20-30^{\circ} \mathrm{C}$, durante 8-16 horas respectivamente (Brasil, 1992). As avaliações foram realizadas a cada dois dias após a semeadura, sendo finalizadas ao término do $30^{\circ}$ dia. Após este período empregou-se o teste de tetrazólio, conforme metodologia já citada de Malavasi et al. (2001), utilizando-se os 10 tratamentos, com as cinco repetições de 25 sementes por tratamento.

Considerando-se que a viabilidade indica que a semente pode germinar em condições favoráveis de ambiente (Marcos-Filho et al., 1987) ou ainda, que sementes viáveis são aquelas capazes de originar plantas normais (Brasil, 1992), neste trabalho será empregado o termo 'percentagem de sementes vivas', adaptação do termo 'vitalidade de sementes' que segundo Marcos-Filho et al. (1987) significa que a semente está viva, mas dormente.

Para análise estatística os tratamentos foram arranjados em esquema fatorial $2 \times 5$ (método de extração de arilo de sementes $x$ concentrações de ethephon), sendo os dados submetidos à análise de variância e as médias comparadas pelo teste de Tukey, a 1\% de probabilidade (Gomes, 1990).

\section{RESULTADOS E DISCUSSÃO}

Os resultados referentes ao efeito dos tratamentos nas sementes de $P$. giberti N.E. Brown encontram-se na Tabela 1 e Figura 1.

De acordo com os resultados pode-se verificar na Tabela 1 a ocorrência de interações significativas entre as concentrações de ethephon e os métodos de extração do arilo na 
TABELA 1. Dados médios de percentagem de vitalidade (sementes vivas dormentes) de maracujá (Passiflora giberti N.E. Brown) submetidas à dois métodos de extração de arilo e embebição em diferentes concentrações de ethephon.

\begin{tabular}{cccc}
\hline \multicolumn{4}{c}{ Vitalidade (\%) } \\
\hline Concentrações $\left(m g . .^{-1}\right)$ & Fermentação & Fricção & Média \\
\hline zero & $86 \mathrm{Aa}$ & $74 \mathrm{Aa}$ & $80 \mathrm{ab}$ \\
150 & $87 \mathrm{Aa}$ & $69 \mathrm{Ba}$ & $78 \mathrm{ab}$ \\
300 & $88 \mathrm{Aa}$ & $83 \mathrm{Aa}$ & $85 \mathrm{a}$ \\
450 & $86 \mathrm{Aa}$ & $80 \mathrm{Aa}$ & $83 \mathrm{ab}$ \\
600 & $65 \mathrm{Bb}$ & $81 \mathrm{Aa}$ & $73 \mathrm{~b}$ \\
\hline Média & $82 \mathrm{~A}$ & $78 \mathrm{~A}$ & \\
CV $(\%)$ & 12 & & \\
\hline
\end{tabular}

Médias seguidas pela mesma letra, maiúsculas para método de extração das sementes e minúsculas para a embebição em ethephon, não diferem significativamente entre si pelo teste de Tukey, a $1 \%$.

percentagem de sementes vivas dormentes, sendo que somente quando se empregou a extração por fermentação e a maior concentração de ethephon (600mg. $\left.1^{-1}\right)$ obteve-se significativamente a menor percentagem de vitalidade nas sementes (64\% de sementes vivas) do experimento.

Em relação às médias obtidas com as concentrações de ethephon, independentemente do método de extração do arilo, a melhor resposta foi obtida com 300mg. $1^{-1}$, a qual diferiu significativamente da concentração de $600 \mathrm{mg} .1^{-1}$, que obteve, também o pior desempenho quando foi associada com o método de extração por fermentação, conforme Tabela $1 \mathrm{e}$ Figura 1.

Estes resultados demonstram que o uso de elevadas concentrações de ethephon em conjunto com o método de extração por fermentação acarretou diminuição na vitalidade das sementes de Passiflora giberti, que variou de $86 \%$ na testemunha para $65 \%$, quando houve a imersão de sementes em $600 \mathrm{mg} . \mathrm{l}^{-1}$ de ethephon e nenhum outro tratamento diferiu da testemunha.

Marcos-Filho et al. (1987) verificaram que $300 \mathrm{mg} \cdot 1^{-1} \mathrm{de}$ ethrel foi suficiente para superar a dormência de sementes de quatro variedades de girassol, o que se assemelha, também, às respostas de vitalidade obtidas com $300 \mathrm{mg} .1^{-1}$ neste experimento. Tal fato deve ser visto simplesmente como uma referência, uma vez que se trata de outra espécie.

Em relação ao uso de ethephon para estimular a germinação de sementes de $P$. giberti, Ferreira (1998) obteve 40\% de germinação quando empregou $150 \mathrm{mg} \cdot 1^{-1}$ de ethephon, o que diferiu significativamente da testemunha $(21 \%$ de germinação). Por outro lado, quando se utilizou 300 $\mathrm{mg}^{-1}{ }^{-1}$ obtevese uma germinação média de $25 \%$, o que não diferiu da testemunha, mas da concentração de $150 \mathrm{mg} .1^{-1}$ de ethephon. Estes dados não estão de acordo com os obtidos neste trabalho, pois diferentemente de Ferreira (1998), a porcentagem de germinação foi nula.
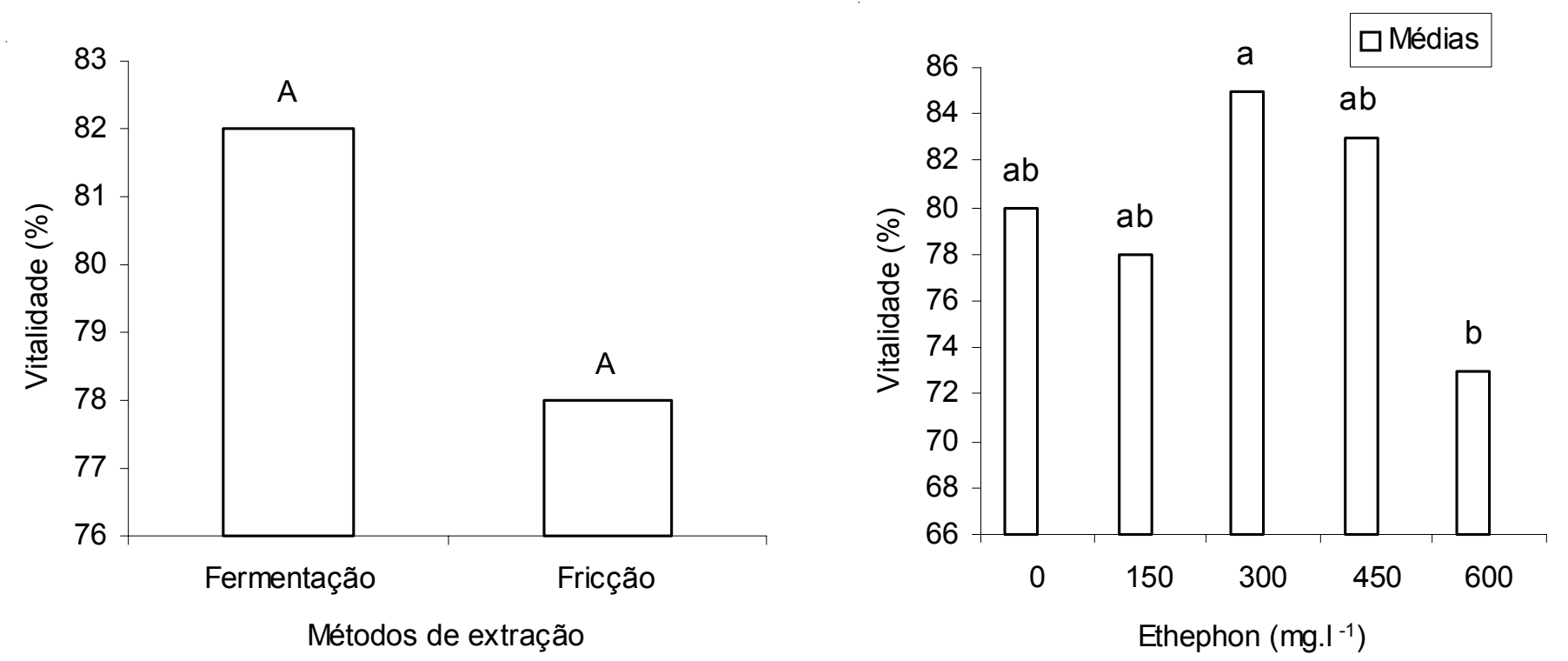

FIG. 1. Média de percentagem de vitalidade (sementes vivas dormentes) de maracujá (Passiflora giberti N.E. Brown) em função de dois métodos de extração do arilo e de concentrações de ethephon. Médias seguidas pela mesma letra maiúscula não diferem entre si pelo teste de Tukey, a 1\%. 
Verifica-se portanto que há uma grande variabilidade genética na espécie, ou algum mecanismo de dormência que merece ser melhor estudado. Pois embora se tenha obtido em média $85 \%$ de vitalidade nas sementes com $300 \mathrm{mg}^{-1} \mathrm{l}^{-1}$ de ethephon neste experimento, Ferreira (1998) obteve incremento na percentagem de germinação, de $P$. giberti em relação a testemunha quando empregou $150 \mathrm{mg} .1^{-1}$, conforme discutido anteriormente Por outro lado, o mesmo autor verificou que $300 \mathrm{mg} .1^{-1}$ diminuiu significativamente a percentagem de germinação das sementes e neste experimento tal concentração manteve a vitalidade das sementes igual a testemunha, porém nenhuma concentração foi suficiente para estimular a germinação e superar a dormência.

Deste modo, pode-se dizer que existe dormência nas sementes empregadas neste trabalho, pois os resultados estão de acordo com as definições encontradas em Brasil (1992), de que as sementes dormentes são aquelas que aparentemente viáveis não germinam, mesmo quando colocadas em condições específicas para a espécie, absorvem água, intumescem e não apodrecem até o final do teste de germinação.

As diferenças observadas entre os trabalhos com a espécie $P$. giberti podem ser explicadas devido a grande variabilidade genética da espécie e a diferentes origens e lotes de sementes, o que poderá ter afetado o balanço hormonal das mesmas. Além destes fatores, as citações de Mattoo \& Suttle (1991) de que o etileno além de parecer superar a dormência em algumas espécies e promover a germinação em outras, é ineficiente em algumas sementes e age negativamente em outras, corroborando para a diferença dos resultados, apesar de serem sementes da mesma espécie.

Analisando-se a Figura 1, nota-se que não houve diferença, em média, entre os dois métodos de extração, o que difere das informações de São José \& Nakagawa (1988), os quais obtiveram que a fermentação prejudicou a qualidade de sementes de Passiflora edulis f. flavicarpa, em relação ao vigor, velocidade de emergência, comprimento e peso médio da planta. Porém, neste experimento a fermentação foi prejudicial somente quando se empregou elevadas concentrações de etileno. Por outro lado, os autores verificaram que a fermentação beneficiou a porcentagem de germinação, o que não foi verificado neste experimento.

Observou-se, portanto que com a associação de elevadas concentrações de ethephon e a fermentação das sementes, ocorreu diminuição na vitalidade das sementes, o que indica aumento significativo na porcentagem de sementes mortas.

\section{CONCLUSÕES}

- Os métodos de extração do arilo não afetaram a vitalidade das sementes dormentes de P. gilberti;

- o ethefon em nenhuma das concentrações utilizadas foi eficiente para a promoção da germinação (ou superação da dormência) de sementes de $P$. gilberti;

- apenas a concentração de $600 \mathrm{mg} . \mathrm{l}^{-1}$ de ethephon afetou a vitalidade das sementes dormentes de $P$. gilberti.

\section{REFERÊNCIAS}

ABELES, F.B.; MORGAN, P.W. \& SALTVEIT-JÚNIOR, M.E. Ethylene in plant biology. 2.ed. California: Academic Press, 1992. 414 p.

ALMEIDA, A.M.; NAKAGAWA, J. \& ALMEIDA, R.M. Maturação de sementes de maracujá amarelo: experimento 1. In: CONGRESSO BRASILEIRO DE FRUTICULTURA, 9, Campinas, 1987. Anais. Campinas: Sociedade Brasileira de Fruticultura, 1988. p.625-630.

AKAMINE, E.K.; BEUMONT, J.H.; BOWERS, F.A.I.; HAMILTON, R.A.; NISHIDA, T.; SHERMAN, G.D; SHOJI, K. \& STOREY, W.B. Passion fruit culture in Hawaii. Hawaii: University of Hawaii, 1956. 35p. (Extension Circular, 245).

BRASIL. Ministério da Agricultura e Reforme Agrária. Regras para análise de sementes. Brasília: SNDA/DNDV, CLAV, 1992. $188 \mathrm{p}$.

FELIPPE, G.M. Etileno. In: FERRI, M.G. (ed.). Fisiologia vegetal. São Paulo: EPU-EDUSP, 1979. cap.6, p.163-192.

FERREIRA, G. Estudo da embebição e do efeito de fitorreguladores na germinação de sementes de Passifloráceas. Botucatu: UNESP, 1998. 146p. (Tese Doutorado).

GOMES, F.P. Curso de estatística experimental. 13.ed. Piracicaba: Nobel, 1990. 468p.

KUHNE, F.A. Cultivation of granadillas. Farming in South Africa, Pretoria, v.43, n.11, p.29-32, 1968.

LUNA, J.V.U. Instruções para a cultura do maracujá. Salvador: EPABA, 1984. 25p. (Circular Técnica, 7).

MALAVASI, M.M; FOGAÇA, C.A.; FOGAÇA, L.A. \& FERREIRA, G. Preparo e coloração de sementes de maracujá-doce (Passiflora alata Dryander) para avaliação da viabilidade através do teste de tetrazólio. Revista Brasileira de Fruticultura, Jaboticabal, v.23, n.1, p.126-129, 2001.

MARCOS-FILHO, J.; CÍCERO, S.M. \& SILVA, W.R. Avaliação da qualidade das sementes. Piracicaba: FEALQ/USP, 1987. 230p.

MARCOS-FILHO, J.; YURIKA, H.K. \& BARZAGHI, L. Métodos para superar dormência de sementes de girassol (Helianthus annuus L.). Revista Brasileira de Sementes, Brasília, v.9, n.2, p.65-74, 1987. 
MATTOO, A.K. \& SUTTLE, J.C. The plant hormone ethylene. London: CRC Press, 1991. 337p.

MENEZES, J.T.T.; OLIVEIRA, J.C.; RUGGIERO, C. \& BANZATTO, D.A. Avaliação da taxa de pegamento de enxertos de maracujá-amarelo sobre espécies tolerantes à "morte prematura de plantas". Científica, Jaboticabal, v.22, n.1, p.95104, 1994.

MORLEY-BUNKER, M.J.S. Seed coat dormancy in Passiflora species. Annual Journal, Canterbury, v.8, n.1, p.72-84, 1980.

OLIVEIRA, J.C.; NAKAMURA, K.; RUGGIERO, C. \& FERREIRA, F.R. Determinação de fonte de resistência em passifloráceas quanto à morte prematura de plantas. In:
CONGRESSO BRASILEIRO DE FRUTICULTURA, 8 , Brasília, 1986. Anais. Brasília: Sociedade Brasileira de Fruticultura, 1986. p.403-8.

SÃO JOSÉ, A.R. \& NAKAGAWA, J. Influência do método de extração na qualidade fisiológica de sementes de maracujáamarelo (Passiflora edulis Sims f. flavicarpa Degner). In CONGRESSO BRASILEIRO DE FRUTICULTURA, 9, Campinas, 1987. Anais. Campinas: Sociedade Brasileira de Fruticultura, 1988. p.619-623.

SÃO JOSÉ, A.R. \& NAKAGAWA, J. Efeitos da fermentação e secagem na germinação de sementes de maracujá-amarelo. Revista Brasileira de Sementes, Brasília, v.9, n.2, p.35-43, 1987. 